\title{
Algunas muestras de manuscritos relacionados con la tradición
}

JOAQUÍN DÍAZ

Fundación Joaquín Díaz

Recibido: 11/03/2016. Aceptado: 16/05/2016.

Cómo citar: Díaz, Joaquín, "Algunas muestras de manuscritos relacionados con la tradición”, AIEMH. Revista de la Asociación Internacional para el Estudio de Manuscritos Hispánicos 2 (2016): 1-6

DOI: https://doi.org/10.24197/aiemh.2.2016.1-6

Ante todo debo confesar que mi presencia en esta mesa se debe desde luego a la generosidad de los convocantes del congreso pero también al hecho de administrar desde hace bastantes años un abundante archivo que tiene mucho que ver con los manuscritos y la creación poética. En efecto, a través de los más de 6.000 pliegos que componen ese archivo se podría comprobar que la costumbre de escribir a mano en un papel es algo que atraviesa los tiempos y está relacionado con la necesidad de crear pero también con la de recordar. Nuestro archivo se compone básicamente de papeles impresos, pero alberga también muchos manuscritos, principalmente de los siglos XVIII, XIX y XX entre los que he seleccionado dos ejemplos del siglo XIX que espero sean de interés. Uno, fechado en 1833, son unas "Coplas en honor y alabanza de la Purísima Concepción de María Santísima, Madre de Dios y Señora Nuestra, singularísima Patrona y Protectora de España y sus Yndias". El otro es un cuadernillo que contiene una pastorela popular, para ser representada el día de nochebuena por pastores y para uso de Eugenio Fernández Olmos y su familia, de la Unión de Campos, escrito en 1882.

Comenzaré por este último: creo que para explicarnos la existencia de textos como el que voy a describir, convendría destacar la capacidad creativa y el ingenio como virtudes características del pastor, especialmente del pastor trashumante. El conocimiento imprescindible de tierras y gentes, los largos períodos pasados en soledad, la necesaria habilidad manual, confirieron al pastor desde siempre la posibilidad de reflexionar y narrar después esas reflexiones o cantarlas, acompañándose para ello con instrumentos que él mismo construía. 
Ya he insistido alguna vez por escrito sobre la agudeza y perspicacia del pastor, incidiendo además sobre su concepto del repertorio poético y musical, que se reducía básicamente a dos apartados: lo antiguo -es decir lo que habría nacido o se habría generado antes que él existiera- y lo propio -esto es, lo que él habría inventado-. Por supuesto que ese "inventar" tendría el amplio sentido etimológico del verbo latino "invenire" (encontrar) y por tanto se podrían catalogar en ese apartado todos aquellos temas que él hubiese recogido o encontrado en la tradición y hubiese modificado hasta hacerlos propios. El mejor ejemplo para demostrar ese tipo de apropiaciones sería el de Celestino Martín, trashumante y músico residente en Toro (Zamora), quien llegó a asegurarme en alguna conversación que tuvimos que "La loba parda" era suya; tal convencimiento procedía del hecho de haber añadido al texto romancístico, aprendido de su padre, un diálogo entre un pastor y su amo que también procedía de la tradición. Su aportación, pues, era el zurcido. O sea la capacidad para relacionar dos textos con similar temática y que el resultado final de esa conexión fuese creíble. Cabría, pues, hablar, en primer término, de la facultad del trashumante para distinguir entre lo propio y lo de los demás; entre el mundo interno y el de fuera. La memoria -otro ingrediente indispensable en la cocina tradicional para la conservación y enriquecimiento de las narraciones- parecía ser bagaje ligero y viajaba constantemente con el pastor, sirviéndole de excelente compañía en los ratos de tristeza o de incomunicación. Todo estaría a favor de una poética de sentimientos interiorizados y de mal disimulado orgullo por el trabajo propio, cuando no por el oficio, en el que tanta responsabilidad, esfuerzo y virtudes se desarrollaban. El trashumante debía ser-mucho más que un estante o un labrador- buen conocedor de los caminos y tierras, diplomático en sus relaciones, amigo de los amigos, veterinario obligado, médico improvisado, cazador ocasional, amante y defensor de la naturaleza, etc., etc. No es extraño, por tanto, que los elementos predominantes en la temática del repertorio pastoril fueran siempre preocupación y ocupación obligadas.

El pastor trashumante no era analfabeto. Por regla general, tampoco los estantes lo eran: debían conocer el nombre de todos los pagos, caminos y sendas por las que atravesaba su ganado y la posibilidad de interpretar los letreros, los anuncios o los bandos no era ningún lujo. Aunque esta corderada manuscrita está recogida en el siglo XIX, mantiene un tono dieciochesco y un estilo directo que le dan un carácter popular y la hacen tan ingenua y atractiva como un auto medieval. Probablemente el texto 
original es debido a una pluma experta, tal vez la de un poeta, un escritor de comedias, un cura, o las tres cosas al mismo tiempo. Este tipo de textos sirvieron para alimentar la costumbre de representar unos autos que todavía existen hoy en tiempo de Navidad.

A este respecto relataré una anécdota, que me ocurrió hace más de treinta años con unos pastores estantes de la tierra llana leonesa. Habiéndome enterado de que todavía se representaba en el pueblo de Villabraz una Pastorada con diálogos y villancicos, me puse en contacto con el "director" de la función -uno de ellos, que guardaba celosamente el manuscrito de la obra y que se encargaba de los ensayos- para preguntarle la posibilidad de que ese año acudiesen a una iglesia de Valladolid el día 24 de diciembre para representar allí la obra. Pronto me di cuenta de que aquello de lo que hablábamos no tenía nada de "representación" y que lo que preparaban unos meses antes constituía un hecho único en el que no existían "actores", sino pastores. Es decir, no había simulación sino reproducción exacta de un hecho real. Con dificultad pude convencerle de que, si uno de los días anteriores a la nochebuena pudiesen hacer un ensayo en la iglesia de Valladolid, les vendría bien para que todo saliera perfectamente el día de autos. Tuve que ir venciendo dificultades -tendría que ir a buscarles y devolverles a su casa un autobús, tendría que ser a horas que no coincidieran con el ordeño matutino o vespertino, tendría que pagarles un par de pellizas para que fuesen todos iguales porque había alguno que la tenía muy vieja, tendría que asegurarme que la Virgen ante la que se haría el Auto era la del Rosario, que era la suya, etc.- hasta llegar al último grado del proceso. Entonces surgió la pregunta clave: pero ¿quién ofrece la cordera? Porque la costumbre era que la representación se hiciera con la excusa de que alguien del pueblo ofrecía para el rebaño de la Virgen una cordera que tenía que pagar religiosamente por -se supone- algún favor obtenido. Me inventé una razón cualquiera y me dispuse a someterme a la costumbre. Ni se me ocurrió mencionar que el cura que nos dejaba la iglesia me había advertido de que era a condición de no manchar nada y de dejarlo todo como estaba. Bueno, pues después de más de 20 llamadas telefónicas y de dos o tres viajes a Villabraz, se inició la representación o como quiera llamarse el día 21 de diciembre a las 6 de la tarde. A esa hora se abrieron las puertas del templo por donde entraron los pastores cantando. La emoción del momento y lo vistoso de la comitiva me ahorraron percibir que la cordera había dejado, además de varios balidos lastimeros provocados por el estrés de ver a tantos pastores reunidos, innumerables cagalutas en el camino hacia el altar. Acabado el 
canto de entrada se inició el diálogo entre Juan Lorenzo -el pastor díscolo e incrédulo- y el mayoral, en el que éste trataba de convencer a aquél de que había visto la estrella de Belén. Repito que no existía una actuación. Los pastores estaban tan acalorados y discutían tan fuertemente que pensé que se iban a dar con las cachas. Finalmente Juan Lorenzo, en un arrebato temperamental cogió la olla en la que se supone que se estaban cociendo unos garbanzos al fuego y pegó un cacharrazo tan fuerte en el presbiterio que no hubo rincón de la iglesia que no recibiera el impacto de algún tito de los que salieron disparados. Iba a decir "y colorín colorado" porque esto parece un cuento pero el cuento vino después cuando tuve que recibir los reproches del cura por haber organizado un acto tan desorganizado. Recordé en ese momento la cantidad de pueblos en los que se me había dicho: "dejamos de hacer la pastorada en la iglesia porque el cura nos lo prohibió" (bien es verdad que en alguno se me dijo también: ya ves, por hacer una lumbre en la iglesia se pone así). Sin embargo lo que me convenció definitivamente del aserto anterior de que el pastor unía su vida y su oficio fue el comentario de uno de ellos sobre el tema de las prohibiciones: "Si es mejor así, hombre, que Jesucristo nació en medio del campo o todo lo más en una tenada. Lo de la iglesia está fuera de lugar".

Bueno, pues anécdotas aparte, ese texto tan querido y tantas veces revivido por los pastores solía ser anotado por el director del auto que recordaba todos los papeles y se sabía de memoria la obra, a la que añadía en ocasiones alguna acotación, como por ejemplo: "Aquí lo toma Herodes como a burla y sale de su palacio dando voces como un loco, despachando correos en busca de los Reyes Magos, y va un mensajero a Belén a preguntar por los Reyes y dice el mensajero: ¿Han visto por aquí pasar los tres Reyes de la Arabia? Desengañarme, que Herodes está que rabia..." 


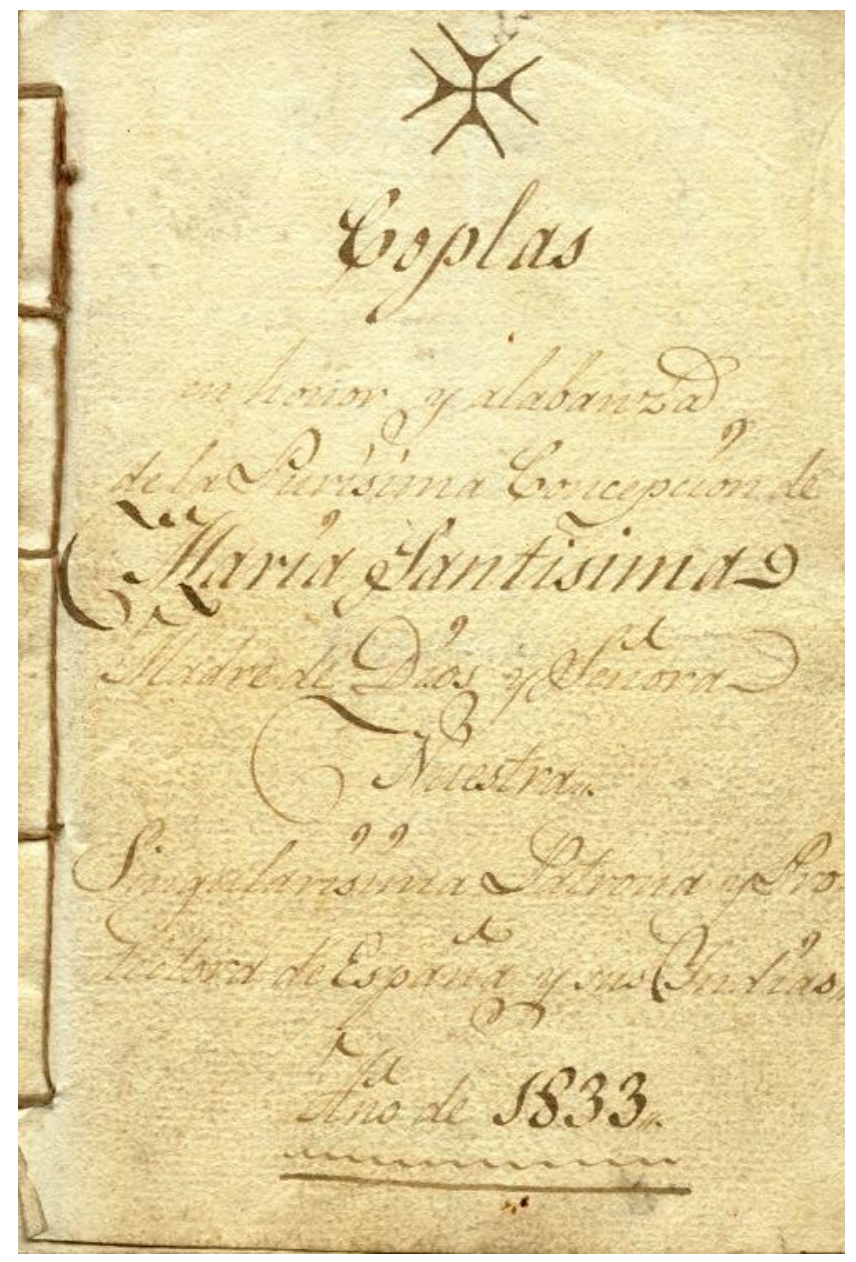

El segundo manuscrito, junto con otras documentaciones muy interesantes, lo encontré en una tienda de antigüedades. El anticuario me ofreció el lote casi a la desesperada antes de venderlo al peso porque se lo había presentado ya a alguna Universidad y lo había rechazado (tal vez por el precio). A pesar de mi interés por conocer la procedencia y el proceso para que hubiesen llegado esos manuscritos a la tienda, el anticuario no me contestó nunca. Sin embargo, supe por otro lado que ese señor tenía una hermana Clarisa, priora o abadesa en un monasterio del sur y probablemente le habría requerido para valorar y vender algunos cuadros e imágenes de determinados conventos de la orden (esto parece algo en contra de todas las leyes de patrimonio pero se ha hecho muy a menudo porque esas órdenes dependen directamente de Roma y no del Ordinario). 
Supongo que entre las cosas "sin valor" (o sea sin el valor económico de un cuadro o una talla) estaba el archivo -archivo musical, por cierto, con tan destacado valor que se ha convertido en materia de estudio en la Universidad Complutense-, que el anticuario se llevaría a última hora y con pocas esperanzas de convertirlo en algo vendible, dado el escaso interés que hay en España por el papel antiguo.

De cualquier manera estamos probablemente ante unas coplas compuestas por un maestro de capilla para conmemorar en el convento de Sevilla una festividad solemne de acendrada tradición. En nuestro mismo archivo se encuentran otras coplas a la Inmaculada (lo que demuestra la popularidad del tema desde dos siglos antes) en cuyo encabezamiento se puede leer: Coplas en alabanza de la Inmaculada Concepción de la siempre Virgen María, Madre de Dios y Señora nuestra, compuestas a devocion e instancias de D. Mateo Vázquez de Leca, Arcediano de Carmona y Canónigo de la Sta. Iglesia metropolitana de Sevilla. Va añadida una alabanza al Santísimo Sacramento, aplicada al Misterio de esta Soberana Señora / por Miguel Cid, natural y vecino de dicha ciudad, donde se imprimieron por primera vez el día 23 de enero de 1625, y de donde se han comunicado después con sumo aplauso á todo el mundo Católico. El pliego del que hablo ahora está publicado por la Viuda de Caro, en Sevilla, en 1830. Es decir, estamos de nuevo ante una tradición muy antigua -en ambos casos desde luego frecuente en el Siglo de Oro, tanto en el caso de la dramatización navideña como en el de las coplas a la Inmaculada- sobre la que un poeta ha creado y manuscrito unos versos que han llegado a nosotros por pura casualidad y después de superar unas dificultades que, sin afán de exagerar, tienden a hacer tan interesante el contexto como el propio texto. Aun sin pretender que la grafología esté por encima de la literatura, habrá que reconocer que aspectos como la elección del soporte -del papel- por parte del autor, las anotaciones en sobrescritura o al margen, la intencionalidad del trazo, o incluso la selección de la guita con que se cosería el cuadernillo a la japonesa, ofrecen aspectos destacados y complementarios en el estudio de estos manuscritos. 